\title{
Risk Management Method of Project Induced based on Market Demand Analysis
}

\author{
Xian Wang \\ Department of Technical Economics and Management, Xi'an University of Technology, Xi'an, China
}

Keywords: Demand Analysis, Analysis Induction, Market Risk, Risk Management, Project Management.

\begin{abstract}
Current researches on project management focus on studying the project content scope and management method, while there are few researches on the project image presentation. This paper follows modular thinking, proposes the concept of project image risk management from the perspectives of system theory and organization theory, describes all project image management activities from time dimension, factor dimension and relation dimension, analyzes categories and features of project image risk, sets up dynamic evaluation and management model for project image risk and provides a new idea for multi-dimensional analysis and life cycle management of high technology project risk.
\end{abstract}

\section{Introduction}

Current researches on project management either focus on the attention to project process management or focus on research and design for activities within project knowledge module. Current researches on project management mainly focus on studying project content scope and management method, but few of them study the project image presentation. In view of a large number of hi-tech project management cases, the influence of the quality of project image management performance on the success of the project can't be ignored.

Based on the idea of system theory, this paper puts forward to concept of project image risk management, analyzes the reasons and classification features of project image risk, sets up model frame for project image risk evaluation management and makes research on project image risk management.

\section{Summary of Image Management}

Image management refers to a series of activities made for setting up "proper" image for one organization. Green believes that image management refers to "formal combination of various capabilities and skills used to protect the reputation of the company". This reputation may be the organization itself or may be the brand (or trademark) owned by the organization. Green regards crisis management as the final result of reputation risk management. In a narrow sense, it is correct if treat crisis as the product of lacking reputation management, but actually, crisis management is far beyond this.

Image management is the new demand of development of contemporary economic and social forms for complicated management activities. The reason why does image management draw great attention from western management circle and enterprises in recent years is that the integration of world economy, progress of information technology and other factors cause fundamental reforms to economic form, which transfers the management viewpoint from vertical question to horizontal questions. The image management issue for project has been upgraded to an important position.

American scholar Archibald proposes concepts of image, image event and key image etc in project management as well as simple steps of implementing image management. He divides projects image into six categories, including responsibility change image, action result image, manage brand image, customer image, information image and material image. 
Domestic scholars make few researches on image management and they mainly make researches on organizational change and enterprise management. For example, Tian Yezhuang and others study the plastic mechanism of organizational boundary, discuss related problems of organizational boundary barrier, organization membrane and organizational boundary penetration and make brief description for the features of organizational boundary and interdepartmental boundary.

Yong Tianrong defines image management in one brand new field as a brand new concept. Image management is a new branch of management and the basic subject of its establishment is public relations. At the same time, it is with stronger superiority and practicability of subject than public relations. Image management is the internal demand of public relations development as well as logical and natural extension.

It can be seen from the above that foreign researches on image management at present have been expanded from enterprise management field to project management field, but we still focus on enterprise management field. Project management integrates a lot of management methods and technologies, which have been applied extensively in the world. The core of project management is project risk management. There is still no research on project image risk management. In view of the practice of project management, an outstanding problem existed in our country is that there are a lot of not interoperable problems existed between project management modules, which is not good for the image effect of the whole project management and also reflects the problem of image risk management existed between management modules. Therefore, this paper sets up the concept of project image risk management and explores the features and rules for the generation and development of project image risk, which is of great theoretical and practical significance.

\section{Project Image Risk Management}

The image risk management studied in this paper is an idea of modular management risk, which runs parallel with theoretical method of traditional risk evaluation and management and composes the analysis basis of project image risk management. The previous risk recognition methods usually divide risk into technology risk, plan risk, supportability risk, expense risk, progress risk, market risk and law risk etc; Qi Anbang divides project risks into project definition and decision risk, project organizational risk, project scope risk, project duration risk, project cost risk, project quality risk, project integration risk, project communication risk, project human resources risk and project purchasing risk based on basic knowledge module in project knowledge system.

These classification methods mainly study the contents of risk management from static perspective, but they do not answer specific position where risk happens or may possibly happen. The idea of image risk management is to divide all activities of project management into several process modules or management modules. In the image processing of module, it analyzes and positions risk factors and their features, which not only focuses on answering what is project risk, but also strives to answer where does risk take place, and then makes clearer and more visualized control for internal and external project risk.

To make it easy for description, this paper defines project image management activities from three dimensions. Any project has life cycle, so what has been expressed by various management activities of project in time dimension is project progress image or project node image (node image includes constraint information of one successful project for project time progress, budget cost and project performance at this node; the operation of any project needs to invest some resource factors, such as funds or capital, knowledge or technology, material and manpower etc), therefore, the expression of project management activities in factor dimension can be described by resource image; any project has stakeholders, for example, it needs to consider about the interest of project investor (shareholder) or demand of project for object; on the other hand, the operation of project must be organized by project manager, functional manager and other managers. Therefore, the expression of project management activities in relation dimension can be expressed by various relation images.

The additional inputs for project process image in project image risk management can promote the progress or node of the project; timely communicating and coordinating the relation between investor and clients can clarify project demand in a better day and then promote the overall progress 
of project.

There are generally three relations between project images, tandem image, feeder image and intermediary image. Generally speaking, time node image is the sequence arrangement of project activities in time, which is presented as one-way flow of project management information, therefore, it belongs to tandem image; the resource image in factor dimension and relation image in relation dimension are presented as bidirectional interaction of information, which mainly belong to feeder image. There are also images without direct relation, but connected together through some resource centers, which can be called as intermediary image. Therefore, the node image in time dimension representation mainly belongs to tandem image, the resource image in factor dimension basically belongs to intermediary image, and the relation image in relation dimension basically belongs to feeder image.

In the project management practice, following three image risks appear frequently.

1. Structural image risk, structural image risk is to divide project into serveral working units to form tree structures, including software, hardware and other work packages. Structural image risk refers to that due to the not scientific and not clear work breakdown for project at preliminary planning stage, it causes cross and overlapping in some modules in the project progress process, problems happen to structural image and it will take up some resources.

2. Information transmission image risk, it is the mismatching between the information expression of one work module and information format requested by the next work module, and then causes project module information transmission image risk.

3. Preference image risk, it is management risk caused by the unclear functional boundary among project manager, functional manager and other managers or individual management preference. Sometimes, manager dynamic risk is also called as manager weakness risk. Any incapability of project manager may cause potential dynamic risk to project manager, which can't well handle the coordination and connection between project modules and then cause the generation of project image risk.

For the above three image risks, the first two belong to node image and resource image, which are caused by unclear project planning and will cause the change of project resource configuration due to the node image risk. The dynamic risk of manager is mainly produced in various relations. Therefore, research on project risk management can starts from three dimensions of time, factor and relation and analyze integrated features of project image risk generally. According to the project progress, it is easy to divide the node image of project. But at each project node, the conflicts between resource factors of project investment and stakeholders that need to be handled in priority are different, so the risk integration features of each node image are different, in which the importance degrees of risk factors are also different. Therefore, it has to distinguish the key image of project at each node (or core image), which are images with high risk. Make key risk analysis and tracking control. This is the basic idea of project image risk management model.

\section{Research on Project Image Risk Management Model}

The key for establishing project image risk management model lies in establishing project risk set, image set and confirming the recognition tool of risk and image. Risk set is the set of all risks that may possibly happen in project operation process; image set refers to the set of all images in three dimensions in the whole project operation process. Risk of project at each image includes risk set of numerous risk factors. Project risk recognition and image recognition mainly adopts perceived risk and analysis risk. Perceived risk is to understand various risks of objective existence and it is the basis of risk recognition. Only through perceived risk, it can make further analysis on this basis, seek for factors that cause risk accidents and make risk management decision service for planning risk processing program. Analysis risk is to analyze various factors that cause risk accidents. It is the key of risk recognition.

Risk level description: high risk: has important influence on project expense, performance and progress and has to take action priority processing. Middle risk, has certain influence, may adopt special measures and needs to pay special attention in management; Low risk, needs to continue to 
supervise, is risk and continues to keep low risk.

For the management of project risk or project image risk, generally, it should set up special project risk management team on the basis of original project management organization. Risk management team is composed of project managers, functional managers, technical experts and management consulting experts etc.

Image risk management is an integrated method for dynamic management risk. The effect of every image risk management affects the effect of the whole project risk management directly. Therefore, it is very important to process the information of image risk management feedback correctly. Project image risk management feedback is to record the main information of project interface continuous risk management accurately in details, set up standard file for project image risk management and import project image risk management information into project risk information database for future reference timely.

\section{Conclusions}

Due to the multidimensional and life cycle analysis features of project image risk management, this paper is with important application value for risk management model. In the process of project management, we try to use risk analysis method to implement project image risk evaluation and control, which can not only evaluate the features and influence of various static risk that project image may possibly met, but also position key image risk in the whole project life cycle with effective adoption of expert evaluation mechanism. Make monitoring management for risks with continuous risk management method, and then decrease the cost of project image risk management and improve project image risk management as well as the economic benefits and social benefits of the whole project management.

\section{References}

[1] Jennifer W. Chan, Yingyue Zhang, and Kathryn E. Uhrich, Amphiphilic Macromolecule Self-Assembled Monolayers Suppress Smooth Muscle Cell Proliferation, Bioconjugate Chemistry, 2015, 26(7), 1359-1369.

[2] Yingyue Zhang, Evan Mintzer, and Kathryn E. Uhrich, Synthesis and Characterization of PEGylated Bolaamphiphiles with Enhanced Retention in Liposomes, Journal of Colloid and Interface Science, 2016, 482, 19-26.

[3] Yingyue Zhang, Ammar Algburi, Ning Wang, Vladyslav Kholodovych, Drym O. Oh, Michael Chikindas, and Kathryn E. Uhrich, Self-assembled Cationic Amphiphiles as Antimicrobial Peptides Mimics: Role of Hydrophobicity, Linkage Type, and Assembly State, Nanomedicine: Nanotechnology, Biology and Medicine, 2017, 13(2), 343-352.

[4] Jonathan J. Faig, Alysha Moretti, Laurie B. Joseph, Yingyue Zhang, Mary Joy Nova, Kervin Smith, and Kathryn E. Uhrich, Biodegradable Kojic Acid-Based Polymers: Controlled Delivery of Bioactives for Melanogenesis Inhibition, Biomacromolecules, 2017, 18(2), 363-373. 